\title{
Cultivating the Innovation Ability of College Students Based on Science and Technology Competition
}

\author{
Shi Mingna \\ College of Music and Performance, Sichuan University of Arts and Science \\ Dazhou, China \\ E-mail: 958957543@qq.com
}

\begin{abstract}
Science and technology competition of college students is a quasi-scientific activity. Science and technology competition provide a favorable platform for college students to cultivate innovation and practical ability. The cultivation of college students' innovation ability is a systematic project, which requires us to analyze the current problems in science and technology competitions and discuss the importance of science and technology competitions in cultivating the innovation ability of college students and then propose to enhance innovation ability of college students taking science and technology competitions as a carrier.
\end{abstract}

Keywords-College Students; Science and Technology Competition; Innovation.

\section{ISSUES ANALYSIS OF CURRENT COLLEGE} STUDENTS SCIENCE AND TECHNOLOGY COMPETITION

With the continuous development of quality-oriented education in colleges and universities, various science and technology competitions have been carried out on campus. Through science and technology competitions, the practical ability and innovation ability of college students are enhanced, and their interest in learning and innovation are developed. However, there are still some practical problems in the process of science and technology competitions.

\section{A. Propaganda of the Competitions is Insufficient}

Good propaganda work of science and technology competitions is the premise of improving the college students' participation sense and encouraging multidisciplinary and interdisciplinary college students to participate in the competition of science and technology competitions. From the current college science and technology competition propaganda, we can see it is not enough, mainly including three aspects: firstly, science and technology competitions do not form effective propaganda mechanism. There are many different kinds of competitions of science and technology, the level of which are not the same, and the organizations are not the same. Therefore, for different types, levels of science and technology competitions, there must be the corresponding institutions being responsible for the promotion. However, the current colleges have not an effective mechanism of propaganda. Secondly, the current science and technology competition propaganda is just weak, without the contents highlighting the importance of innovation ability, application ability training. This propaganda is difficult to arouse the students' interest and enthusiasm to participate in the competitions. Especially under the grim situation of current university students' employment environment, highlighting the importance of the science and technology competitions in promoting college students' innovation ability, and the team cooperation ability is the intrinsic motivation to simulate college students' enthusiasm to participate in the competition of science and technology. Thirdly, the important roles of guidance teachers in the propaganda of science and technology competitions are not played. Teachers and students can contact closely, and promote the competitions from the perspective of professional work, and even can cause the attention of students. Therefore, no matter what level of science and technology competition activities, teachers must play their important roles in the competition of science and technology.

\section{B. The Power of the Science and Technology Competition GuidanceTeachers is Weak}

"Teacher is the basis of innovation education. To cultivate talents with innovative thinking and innovative ability colleges and universities should rely on the innovation of teachers."[1] To implement innovative thinking education and develop science and technology competitions, we must have a teacher's team with professional background and excellent, innovative ability, as well as innovative consciousness. From the present situation of the teachers participating in college science and technology competitions, guidance of teachers' power is still very weak, mainly including the following three aspects: firstly, the quantity is difficult to meet the requirements of a wide range of science and technology competitions. Under current new situation, there are many different kinds of science and technology competitions and the corresponding preparation period are longer. The majority of classroom teachers have their own teaching tasks. To complete the guidance of the competitions of science and technology, they need to spend their free time and holidays, therefore, there are very few teachers taking the initiative to participate in the competitions. Secondly, professional background is good enough. The current competitions of science and technology have wide thesis, extensive knowledge and adopting so many new technologies, which requires teachers having strong 
professional background, more abundant practical experience, and broader knowledge. In the current overall guidance teachers in college science and technology competitions, quite a number of teachers lack of the ability and quality. Thirdly, guidance teachers lack of innovation consciousness and independent critical spirit. Obsolete education idea, backward teaching contents, methods, and means are still the problems for current teachers in colleges and universities to improve. Therefore, college teachers must follow the trend of the times and enhance their sense of mission and responsibility, the innovation education and cultivation of innovative thinking should be put in important position to enhance students' ability of independent thinking.

\section{Imperfect Incentive Mechanism for Science and Technology Competitions}

Competitions of science and technology usually need to be prepared with relatively long time. So it will need guidance teachers and students to spend considerable time and energy. An unsound incentive mechanism will weaken teachers and college students' motivation and enthusiasm to participate in the competitions. [2] First of all, from the view of college students, current college students' learning task is quite heavy, especially for freshman and sophomore, in addition to spending the normal teaching time learning the required courses, they also need to use weekends for elective courses. Currently, the university campus has busy cultural activities, so many college students participate in a variety of student activities and community activities. In this case, students' interest and enthusiasm is not enough to attracting students spending a lot of time and energy into the competitions. So it must be gave correct guidance and the reward. Secondly, from the perspective of guidance teachers, their main job is the corresponding teaching tasks, and their spare time should be also used for preparing courseware and reviewing homework. In addition, the teachers in colleges and universities also have heavy pressure to complete the corresponding discipline teaching and focus on scientific research, which also occupies a big part of their spare time. As a result, most teachers guide students of science and technology competition at the expense of their free time and holidays. This needs to perfect the related incentive mechanism further, for example, rewarding appropriate credit points for the students participating in the competitions, and counting the guidance work of competitions as part of the scientific research work or recording in the annual performance appraisal and so on.

II. TTHE IMPORTANCE OF SCIENCE AND TECHNOLOGY COMPETITION IN COLLEGE STUDENTS' INNOVATIVE ABILITY TRAINING

\section{A. Stimulate Students' Interest in Learning}

Overall, most of the colleges and universities cultivate still give priority to theoretical knowledge in teaching, and practical communication link is only complementary. In the classroom, the practice often includes experiment or curriculum design, lack of interest and vitality comparing with the extracurricular science and technology competition, which is against stimulating the contemporary college students' interest in learning.[3] Science and technology competitions, to some extent, provide a position to make up the interest of university education. The science and technology competitions require college students to design a systematic and concrete implementation plan according to the different requirements and their own team's understanding of subject analysis, and then validate by the team's actual operation, as well as correct accordingly based on the results of validation, to ensure that the entire team project is more feasible in the implementation process.

In the process of "make plan--verify operationmodification and correction", college students should not only use the power of their teams, but also play their own subjective initiative in the process of teamwork, learning to discover problems, analyzing and solving problems, to use the professional theoretical knowledge learned in the class in actual operation process under the guidance of teachers. In the process, college students can realize that the theoretical knowledge is very useful in the actual operation process. The sense of achievement is to stimulate students' interest in learning. Once students have the motivation to learn theoretical knowledge, they have a strong sense to apply the theoretical knowledge to the actual operation, thus forming a good cycle. In the process, the theoretical knowledge learned by college students cannot only be enriched, but also inspire students learning new knowledge, and their interest and motivation in the field of exploring the unknown.

\section{B. Improve College Students' Innovative Thinking Ability and Practical Ability}

Under current environment, with the deepening of the process of our reform and opening-up, the cultivation of innovative talents is an important goal of colleges and universities for talent cultivation in the new period. "Innovation is the inexhaustible driving force for the prosperity of a country, is the soul of a nation's progress, so the higher education should take cultivating students' innovative thinking ability and practical ability as the key point, and enhancing the comprehensive quality of the whole nation for the purpose." In terms of institutions of higher learning, cultivate the innovative thinking ability and practical ability of college students is to improve college students' exploration spirit for finding knowledge again and cultivate students' comprehensive ability of creative ability, innovation consciousness and recombination.

Competition of science and technology for college students is a strongly systematic, comprehensive innovation practice activity, and it is an important platform to improve college students' innovative thinking ability and practical ability.[4] The competition of science and technology generally requires an innovative design works, such as the national undergraduate electronic design competition requires the college students to conduct innovative research and trial based on daily theoretical knowledge learning, which puts forward higher 
requirements for college students' innovative thinking and innovation consciousness, as well as college students' innovative practice ability. Through the interview with the students participating in the competitions, we found that the most impressive feeling through the competitions was their willpower, enterprising spirit, innovation ability and innovative thinking got a big promotion. The students' desire to explore unknown areas, self-study ability, and the cognitive ability of knowledge has been greatly promoted. The most important thing resulted from the competitions of science and technology is their ability to apply what they have learned and hands-on practical ability has been greatly improved, which is meaningful for the current college students promoting their innovative thinking ability and practical ability.

\section{Cultivate College Students' Team Cooperation Ability}

From the entry requirements and application modes of various current competitions, most of them require participating in the activities in the form of a team. In addition, from the task difficulty of the competitions, all kinds of subjects of science and technology competitions still have certain difficulty, so if you want to complete the topic within the stipulated time in accordance with the requirements, a team with all kinds of talents must be established.

In the competition teams, the work tasks of science and technology competitions should be divided according to different education and major backgrounds and different personality traits. Everyone in the team has a different task and focus, and each member's task is just a branch of the whole team. Therefore, the members should keep in close contact with each other. The team should hold meetings regularly to report their work, progress, and problems in the work. Through the communication between members and team discussions, we can grasp the whole team task schedule and timely solve problems in the process of preparing, and decorate tasks for the next stage, which is the key for a team finishing the competition tasks with high efficiency and high quality in accordance with the requirements of the competition of science and technology within the allotted time. In the process, each member of the team is an important part of science and technology competition, relating to the success or failure. In order to achieve the target together, students work together and cooperate completely, which will not only exercise the participating students' communicative competence, but also cultivate the team cooperation ability of the contemporary college students.

\section{NEW THOUGHT WITH COMPETITION OF SCIENCE AND TECHNOLOGY AS THE CARRIER TO IMPROVE THE INNOVATIVE ABILITY OF COLLEGE STUDENTS}

\section{A. Integration Resources, Establish the Platform Competition of Science and Technology}

At present, the domestic science and technology competitions refer to wide areas. The organization systems of the competitions are also relatively strict (table 1), therefore, resources must be integrated to lay a solid foundation for college students to participate in all kinds of competition of science and technology more professionally, more competitively to build a broader platform.

First of all, establish the base platform for innovation practice. The current college students' science and technology competitions have presented the designing and comprehensive development trend. Setting up independent innovation practice base is the front for exercising college students' hands-on ability, analysis, and problems solving ability. The open laboratories are the innovation practice bases and the practice bases to cultivate high-qualified talents in colleges and universities and also the important field of college student science and technology competitions. With the higher education system reform, the practice and experiment lessons are promoted constantly in university education, providing an important platform for the cultivation of college students' innovative thinking and innovative practice. Some universities have established the all-weather open experimental teaching laboratories, to create a relatively free and loose experimental environment for classroom teachers and students. The teachers and students can go to laboratory in their spare time to improve their homework and communicate knowledge, research problems, as well as find the reasons and solutions. So the cultivation of college students' innovation ability provides a free platform.

Secondly, build a network platform. The network platform of college students' science and technology competitions is the propaganda window and cutting edge position, especially for today when the Internet has been integrated into the college students. So internet must be paid more attentions. To recommend and promote college students' science and technology competitions further, quite a number of colleges and universities take full advantage of modern education technology to set up the platform of science and technology competitions, especially many colleges and universities have established the network interactive platform with rich contents, and complete competitions through optimization and integration. Through the network platform, colleges and universities release all kinds of science and technology competitions notice and demonstrate the organizations, operation and management, progress and achievements to let college students know the conditions of various science and technology competitions easily. Therefore, the competition of science and technology network platforms is the inevitable trend for higher learning organizations organizing competitions of science and technology, which is also the only way to promote college students' innovative ability.

\section{B. Improve the Mechanism to Provide Support and Guarantee for Science and Technology Competition}

First, improve the incentive mechanism. Perfect and reasonable incentive mechanism can greatly promote the guidance teachers and students' enthusiasm to participate in the college student science and technology competitions, but from the current situations that most of the institutions of higher learning lack of support for the competition of science and technology, corresponding mechanism is still not very perfect, whether for the teachers or students. From 
the college students, the appraisal system mainly focusing exam scores is an important factor to restrict the college students' enthusiasm to participate in the competitions of science and technology. The vast majority of the students have to take a lot of time and energy on their professional theory course learning, and there is no more time and energy to participate in the competitions. At the same time, some colleges and universities insufficient reward are another important factor to influence college students to participate in the competitions of science and technology. In terms of the guidance teachers, they not only have heavy teaching task, but also undertake the current research pressure, therefore, they have very limited time and energy to guide the students to participate in the competitions. If in this case, no corresponding incentive mechanism in university, the teachers' and college students' motivation and enthusiasm to participate in the competitions of science and technology will be weakened gradually.

Second, improve the institutional mechanisms. Perfect system is the key to ensure the smooth conduct of college students science and technology competitions.[5] Most of the universities came out a series of systems for science and technology competitions, such as the Administration Measures of The College Students Science and Technology Competitions, Implementing Rules For The College Students Science and Technology Competitions, Project Approval Application System on College Students Science and Technology Competitions, Activities Fund Management Ordinance for College Students Competitions of Science and Technology, etc. In addition, perfect competition organizations should be established from the system to ensure the science and technology competitions conducted smoothly. Encourage and guide students to set up scientific and technological interest clubs or groups and many colleges and universities have established the electronic design association, mathematical modeling association, association of science and technology, building skills association, etc. From the teacher, any guidance of science and technology competitions will take quite a lot of time and effort, so just relying on the guidance of teachers' enthusiasm doesn't work. Therefore, colleges and universities should improve the guidance teachers' enthusiasm from the system, such as have the guidance work of teachers in competitions counted in the year-end appraisal index and annual performance evaluation, or have the work that teachers guiding students participating in the competition connect with their positions and title promotion, to let "want me to guide the science and technology competition" become to "I will guide the science and technology competition".

\section{Optimize Team, to Improve Teachers' Guiding Ability of Competition}

Teacher is the basis of innovation education. Colleges and universities want to cultivate talents with innovative ability and innovative thinking, which basically lies in the teachers' innovation. The teacher with professional ability, high comprehensive qualities is an important condition to develop the innovative ability of college students. Although under the current new concept of higher education, the student has replaced the position of teacher's teaching, but the teacher is irreplaceable for important position in the teaching activities. Teacher's innovation ability and innovation consciousness in the daily teaching penetration directly influence the quality of current innovative education in colleges and universities. It is the key factors to implement innovation education.

First of all, for college student science and technology competitions, the characteristics for wide thesis, strong new technology application, and more involved professional knowledge require teachers having rich practical experience, broad knowledge, and profound professional knowledge. In addition to the guidance teacher's academic level and practical experience, innovation spirit and innovation ability is also the key to directly affect the entry level. Therefore, teachers must have the ability to quickly adapt to the new scientific results, scientific knowledge, having the independent critical spirit and strong sense of innovation.

Secondly, it is easy to overlook 1 point. Teacher's professional moral quality also has the close association with college student competitions. Currently, there are still teachers in colleges and universities lacking of understanding of professional ethics. They are only engaged in the teaching task and blindly for the nonteaching task, which is a typical case of weak working ethic, responsibility consciousness, and sense of mission. Therefore, in enhancing the level of university teachers' professional knowledge and scientific research ability, the teachers' professional quality must be promoted, combining the innovation of teacher education and teachers' assessment and evaluation, to improve teacher's responsibility consciousness and the sense of mission. At the same time, teachers should possess certain dedication spirit, having passion to guide students to participate in the competitions, and guide students against the fear psychology with patience, encouraging students' confidence. Teachers' step-by-step guide is one of the key factors to obtain excellent results in science and technology competitions.

\section{REFERENCE}

[1] Liu Wei. Study on the positive role of science and technology competition in developing college students' innovative thinking [D]. Taiyuan University of Science and Technology, 2013.

[2] Wang Ying. Exploration and study on the competitions of science and technology and innovation ability training [J]. Journal of chemical industry of guangdong province, 2012, (15)39.

[3] Li Xin. College students' motivation analysis of science and technology competitions [D]. Northeastern university, 2010.

[4] Chen Ruisan. Impact analysis of domestic and foreign competitions for college students' innovative motivation of science and technology [J]. Science and technology education innovation, 2013, (7): 128.

[5] Ma Zhong. College students' employment ability training and study based on the competitiona of science and technology [J]. Journal of Jilin institute of education, 2013, (3) 30 